\title{
Synthesis and luminescent properties of nano-sized $\mathrm{Y}_{3} \mathrm{Al}_{5} \mathrm{O}_{12}: \mathrm{Eu}^{3+}$ phosphors
}

\author{
Wei-Tse Hsu, Wei-Hong Wu, Chung-Hsin Lu* \\ Electronic and Electro-Optical Ceramics Laboratory, Department of Chemical Engineering, National Taiwan University, Taipei, Taiwan, ROC
}

Received 3 February 2003; accepted 9 July 2003

\begin{abstract}
Nano-sized $\mathrm{Eu}^{3+}$-activated yttrium aluminum garnet $\left(\mathrm{Y}_{3} \mathrm{Al}_{5} \mathrm{O}_{12}, \mathrm{YAG}\right)$ phosphors were prepared via a simple sol-gel process at as low a temperature as $900^{\circ} \mathrm{C}$. In comparison with the conventional solid-state reaction process, this sol-gel process not only reduced the temperature required for synthesizing YAG:Eu ${ }^{3+}$ powders, but also decreased their particle size to the nanometer range. In the sol-gel process, citric acid and ethylene glycol formed numerous tiny enclosures that trapped the constituent cations, leading to a reduction of the interdiffusion length and an enhancement of the reactivity of the precursors. The photoluminescence intensity of the sol-gel-prepared YAG:Eu ${ }^{3+}$ phosphors was markedly greater than that of the samples derived from the solid-state reaction. This is attributed to the increased crystallinity and improved compositional homogeneity in the sol-gel-derived powders. The photoluminescence characteristics of YAG:Eu ${ }^{3+}$ phosphors were demonstrated to substantially depend on their morphology and particle size.
\end{abstract}

(c) 2003 Elsevier B.V. All rights reserved.

Keywords: Sol-gel; Synthesis; Nano-sized; $\mathrm{Y}_{3} \mathrm{Al}_{5} \mathrm{O}_{12}$; Phosphor; Luminescence

\section{Introduction}

In recent years, inorganic phosphors have been extensively investigated for the applications to various types of display panels, such as plasma display panel (PDP), vacuum fluorescent display (VFD), and field emission display (FED) [1-3]. For enhancing the brightness and resolution of these displays, it is important to develop phosphors with high quantum efficiency, controlled morphology, and small particle sizes. Yttrium aluminum garnet, $\mathrm{Y}_{3} \mathrm{Al}_{5} \mathrm{O}_{12}$ (abbreviated as YAG), is a well-known inorganic compound and is also widely utilized in the optical field. YAG single crystal doped with lanthanides, such as $\mathrm{Nd}^{3+}$, is used in solid-state lasers, and the poly-crystals of YAG doped with different color centers are employed as phosphors in the cathode ray tube (CRT) displays.

Traditionally, YAG phosphors are prepared at high temperatures $\left(>1600^{\circ} \mathrm{C}\right)$ for a long time via a solid-state reaction process. Due to insufficient mixing and the low reactivity of raw materials, several intermediate phases such as

\footnotetext{
* Corresponding author. Tel.: +886-2-363-5230; fax: +886-2-362-3040.

E-mail address: chlu@ccms.ntu.edu.tw (C.-H. Lu).
}

$\mathrm{Y}_{4} \mathrm{Al}_{2} \mathrm{O}_{9}$ (YAM) and $\mathrm{YAlO}_{3}$ (YAP) easily exist in the products [4]. Repeated grinding and calcination are required to eliminate these intermediate compounds, thus increasing the consumption in time as well as energy. For overcoming the drawbacks of the solid-state reaction process, several wet chemical methods such as co-precipitation [5,6], combustion $[1,2]$, and spray pyrolysis $[7,8]$ have been developed to fabricate the YAG-based phosphors. Although YAG can be obtained at low temperatures via these methods, further annealing at high temperatures $\left(\sim 1400^{\circ} \mathrm{C}\right)$ is required to improve the luminescent properties of the powders. Recently, a sol-gel process using metal alkoxides has also been used for synthesizing YAG phosphor $[9,10]$. However, this process is complicated due to the difficulty in handling of alkoxides.

A simple sol-gel process using citric acid and ethylene glycol as the gelation agents was adopted to fabricate nano-sized YAG:Eu ${ }^{3+}$ phosphors in this study. This process has been used for the preparation of ceramic powders $[11,12]$ and silica hybrid materials $[13,14]$. In this process, metal nitrates or carbonates are used as the starting materials; therefore, the problems of handling moisture-sensitive alkoxides can be avoided. Furthermore, different cations can be mixed to the quasi-atomic level that allows the precise control of the chemical composition. In this study, the 
preparation of the nano-sized YAG:Eu ${ }^{3+}$ phosphors via the sol-gel process was investigated. The relation between the photoluminescent properties of the sol-gel-derived powders and the preparation conditions as well as the particle size was discussed. The sol-gel-derived YAG:Eu ${ }^{3+}$ phosphors and those prepared via the solid-state reaction process were also compared in terms of their emission properties.

\section{Experimental}

In the sol-gel process for preparing YAG:Eu ${ }^{3+}$ phosphors, yttrium nitrate and aluminum nitrate were dissolved in deionized water, and europium oxide was dissolved in dilute nitric acid. The prepared solutions were mixed according to the chemical formula of $\mathrm{Y}_{2.85} \mathrm{Eu}_{0.15} \mathrm{Al}_{5} \mathrm{O}_{12}$ with 5 at.\% europium ions doped with respect to yttrium ions. The molar concentration of all metal ions in the solution was adjusted to $0.2 \mathrm{M}$. Citric acid and ethylene glycol in a 1:1.5 ratio were employed as gelation reagents, and the molar ratio of all metal ions to citric acid was maintained at 1:3. The solutions of metal nitrates and citric acid were mixed and stirred for $1.5 \mathrm{~h}$, followed by adding ethylene glycol, and then the solution was heated to $130^{\circ} \mathrm{C}$ on a hot plate for $1.5 \mathrm{~h}$. The solution was evaporated at $300{ }^{\circ} \mathrm{C}$ to initiate the gelation reaction. A large amount of brownish gas was emitted, and the clear solution became yellowish white dry gels. The precursor powders, obtained by grinding the dry gels, were later calcined in the range of $800-1400{ }^{\circ} \mathrm{C}$ for $2 \mathrm{~h}$. On the other hand, $\mathrm{Y}_{2.85} \mathrm{Eu}_{0.15} \mathrm{Al}_{5} \mathrm{O}_{12}$ phosphor was also prepared via the conventional solid-state reaction method. The constituent oxides were mixed in ethanol using a ball-mill for $24 \mathrm{~h}$. The slurry-like mixtures were dried in a vacuum-rotation dryer. The dried powders were calcined at $1500{ }^{\circ} \mathrm{C}$ for $4 \mathrm{~h}$ and then milled. The calcination and milling processes were repeated for three times. The formed phases in the synthesized powders were analyzed using an X-ray diffractometer (MAC science, MXP3). The morphology and the particle sizes of the powders were examined using a scanning electron microscope (Hitachi, S-800). The photoluminescence properties of the powders were investigated using a fluorescence spectrometer (Hitachi, F-4500). A $150 \mathrm{~W}$ Xe lamp was used as a multi-wavelength light source.

\section{Results and discussion}

The precursors prepared from the sol-gel process were yellowish powders. After $800^{\circ} \mathrm{C}$ calcination, these precursors became white powders, implying that organic compounds were burned away during calcination. Fig. 1 illustrates the X-ray diffraction patterns of YAG: $\mathrm{Eu}^{3+}$ calcined at various temperatures from 800 to $1400^{\circ} \mathrm{C}$ for $2 \mathrm{~h}$. From the XRD patterns, it was found that the powders were still

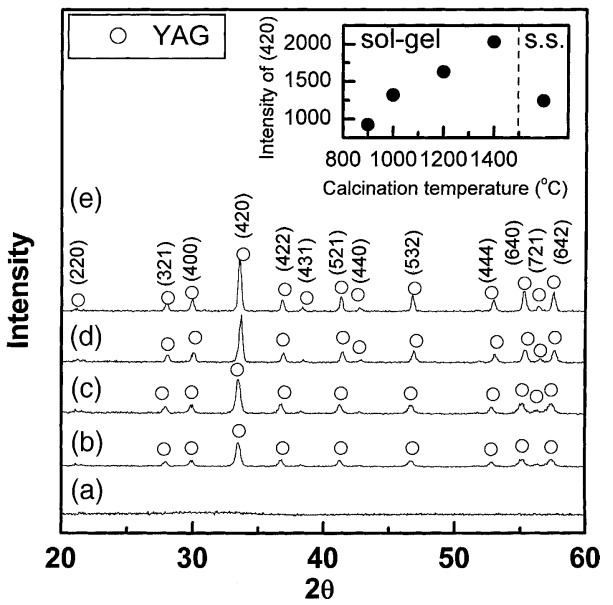

Fig. 1. XRD patterns of the sol-gel-derived precursors of $\mathrm{Y}_{2.85} \mathrm{Eu}_{0.15} \mathrm{Al}_{5} \mathrm{O}_{12}$ calcined at (a) $800{ }^{\circ} \mathrm{C}$, (b) $900{ }^{\circ} \mathrm{C}$, (c) $1000^{\circ} \mathrm{C}$, (d) $1200{ }^{\circ} \mathrm{C}$, and (e) $1400^{\circ} \mathrm{C}$ for $2 \mathrm{~h}$. The inset shows the corresponding intensity of the (420) peak of $\mathrm{Y}_{2.85} \mathrm{Eu}_{0.15} \mathrm{Al}_{5} \mathrm{O}_{12}$ prepared via the sol-gel process and the solid-state reaction (S.S.).

amorphous at $800^{\circ} \mathrm{C}$. However, when the calcination temperature reached $900{ }^{\circ} \mathrm{C}$, the cubic garnet phase of YAG [15] was formed. The obtained diffraction pattern was well consistent with the data reported in ICDD [15], indicating that the single phase of YAG:Eu ${ }^{3+}$ was successfully prepared at a temperature as low as $900{ }^{\circ} \mathrm{C}$. It is noted that no intermediate phases were formed between 800 and $900{ }^{\circ} \mathrm{C}$, implying that the sol-gel-derived precursors were directly transformed into the crystalline YAG phase during calcinations. When the calcination temperature was increased, the diffraction intensities of the calcined powders increased (as shown in the inset of Fig. 1), and the width of the diffraction peaks decreased. The above results reveal that the crystallinity of the powders was enhanced with a rise in the calcination temperature. The white color of the prepared powders suggested that they had no absorption in the visible light range.

YAG: $\mathrm{Eu}^{3+}$ phosphors were also prepared via the solid-state reaction process. As shown in Fig. 2, after the first calcination at $1500^{\circ} \mathrm{C}$ for $4 \mathrm{~h}$, one impure phase, $\mathrm{Y}_{4} \mathrm{Al}_{2} \mathrm{O}_{9}$ (YAM), coexisted with the YAG phase. After the second milling/calcination process, the impure YAM phase still remained in the sample. When the milling and calcination $\left(1500^{\circ} \mathrm{C} / 4 \mathrm{~h}\right)$ process was repeated three times, pure YAG: $\mathrm{Eu}^{3+}$ phase was obtained. On the contrary, the results in Fig. 1 demonstrate that the required temperature for synthesizing pure YAG:Eu ${ }^{3+}$ phosphors in the sol-gel process was much lower than that in the solid-state reaction process. This is attributed to the improved compositional homogeneity and the enhanced reactivity of the sol-gel-derived precursors, thereby reducing the required heating temperature for preparing YAG: $\mathrm{Eu}^{3+}$ phosphors.

The microstructures of YAG:Eu ${ }^{3+}$ powders prepared via the solid-state reaction process and the sol-gel process are shown in Fig. 3. After repeated milling and calcination $\left(1500^{\circ} \mathrm{C} / 4 \mathrm{~h}\right)$, the solid-state-derived YAG:Eu ${ }^{3+}$ powders 


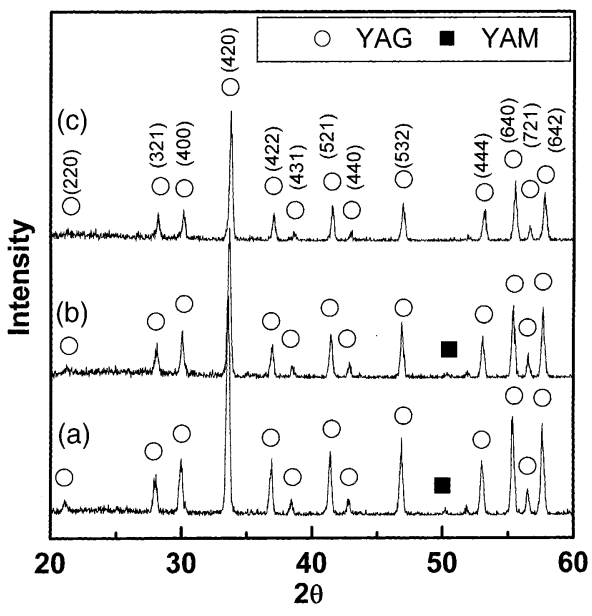

Fig. 2. XRD patterns of $\mathrm{Y}_{2.85} \mathrm{Eu}_{0.15} \mathrm{Al}_{5} \mathrm{O}_{12}$ phosphors obtained via the repeated solid-state reaction process. Calcination at $1500^{\circ} \mathrm{C}$ for $4 \mathrm{~h}$ was repeated for (a) one time, (b) two times, and (c) three times.

exhibited a rounded morphology with a size of around 2-2.5 $\mu \mathrm{m}$ (see Fig. 3(a)). On the other hand, the particle size of $900^{\circ} \mathrm{C}$-calcined powders prepared via the sol-gel process was around $40 \mathrm{~nm}$ (as shown in Fig. 3(b)). With a rise in the calcination temperatures, the particles of the prepared powders enlarged. When the calcination temperature reached $1400{ }^{\circ} \mathrm{C}$, the particle size of $\mathrm{YAG}: \mathrm{Eu}^{3+}$ powders increased to $200 \mathrm{~nm}$, and their shape became nearly spheri-

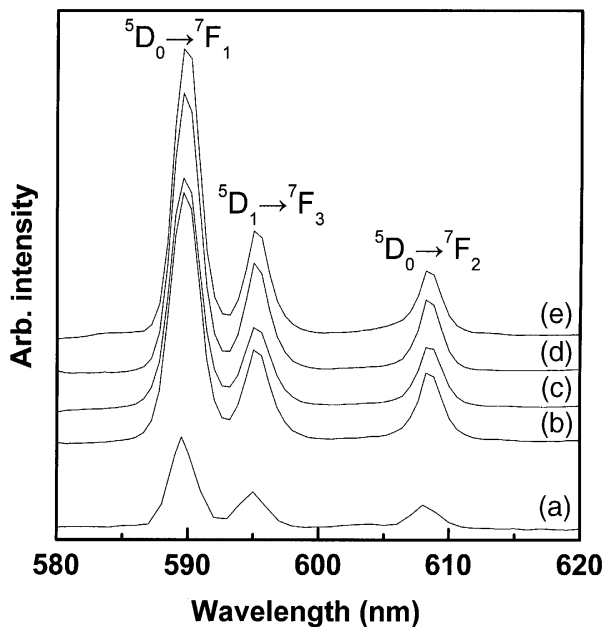

Fig. 4. Emission spectra of (a) the solid-state reaction derived $\mathrm{Y}_{2.85} \mathrm{Eu}_{0.15} \mathrm{Al}_{5} \mathrm{O}_{12}$ phosphors, and the sol-gel-derived $\mathrm{Y}_{2.85} \mathrm{Eu}_{0.15} \mathrm{Al}_{5} \mathrm{O}_{12}$ phosphors calcined at (b) $900^{\circ} \mathrm{C}$, (c) $1000^{\circ} \mathrm{C}$, (d) $1200^{\circ} \mathrm{C}$, and (e) $1400^{\circ} \mathrm{C}$ for $2 \mathrm{~h}$. The excitation wavelength is $250 \mathrm{~nm}$.

cal (see Fig. 3(d)). It was also observed that the particle size of YAG:Eu ${ }^{3+}$ powders synthesized via the sol-gel process was much smaller than that of the powders prepared from the solid-state reaction process.

Fig. 4 depicts the emission spectra of the sol-gel-derived YAG: $\mathrm{Eu}^{3+}$ phosphors calcined at temperatures ranging from 900 to $1400^{\circ} \mathrm{C}$ under the excitation of $250 \mathrm{~nm}$ UV light. The
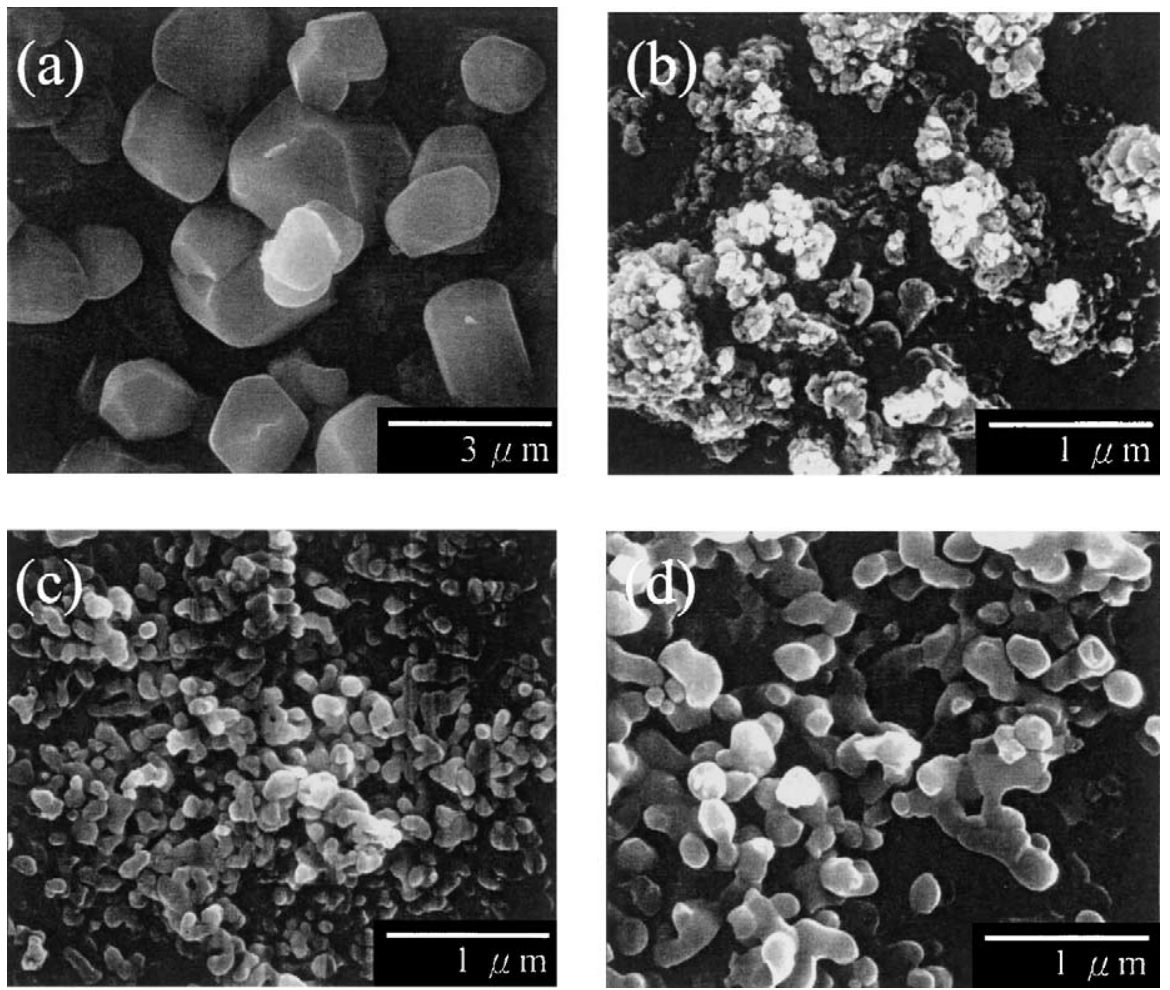

Fig. 3. SEM micrograph of (a) the solid-state reaction derived $\mathrm{Y}_{2.85} \mathrm{Eu}_{0.15} \mathrm{Al}_{5} \mathrm{O}_{12}$ phosphors, and the sol-gel-derived $\mathrm{Y}_{2.85} \mathrm{Eu}_{0.15} \mathrm{Al}_{5} \mathrm{O}_{12}$ phosphors calcined at (a) $900^{\circ} \mathrm{C}$, (b) $1200^{\circ} \mathrm{C}$, and (c) $1400^{\circ} \mathrm{C}$ for $2 \mathrm{~h}$. 
emission spectrum of the powder prepared at $1500^{\circ} \mathrm{C}$ via the solid-state reaction process is also compared in this figure. The powders prepared via these two processes had similar emission spectra except their emission intensity. Three major emission peaks were observed at 590, 594, and $608 \mathrm{~nm}$, revealing the characteristic emission properties of the $\mathrm{Eu}^{3+}$ activators. The greatest emission at $590 \mathrm{~nm}$ occurred from ${ }^{5} \mathrm{D}_{0} \rightarrow{ }^{7} \mathrm{~F}_{1}$ transition of $\mathrm{Eu}^{3+}$. The ${ }^{5} \mathrm{D}_{1} \rightarrow{ }^{7} \mathrm{~F}_{3}$ and ${ }^{5} \mathrm{D}_{0} \rightarrow{ }^{7} \mathrm{~F}_{2}$ transition processes of $\mathrm{Eu}^{3+}$ were responsible for the emissions at 594 and $608 \mathrm{~nm}$, respectively [16-18]. As for the powders prepared via the sol-gel process, the emission intensity of the obtained powders increased with a rise in the calcination temperature because of the enhanced crystallinity. On the other hand, the $800^{\circ} \mathrm{C}$-calcined powders obtained from the sol-gel process did not exhibit any characteristic emission spectrum since the crystalline YAG phase was not formed in this sample, as shown in Fig. 1.

It was found that the emission intensity of the phosphors prepared via the sol-gel process was much higher than that of the powders prepared via the solid-state reaction process. In the sol-gel process, citric acid polymerizes with the ethylene glycol, and these cross-linked organics form a large amount of tiny enclosures that effectively trap the constituent metal ions. Since the sol-gel process provides a more homogeneous environment than the solid-state mixing, the crystallinity of YAG: $\mathrm{Eu}^{3+}$ powders is improved (as shown in the inset in Fig. 1) and the distribution of $\mathrm{Eu}^{3+}$ ions in the YAG matrix is enhanced. The high crystallinity and good distribution of $\mathrm{Eu}^{3+}$ activators reduce the non-radiative relaxation and results in an increase in the emission intensity. The excitation spectra of the emission at $608 \mathrm{~nm}$ of YAG: $\mathrm{Eu}^{3+}$ phosphors prepared via the sol-gel process are illustrated in Fig. 5. The spectrum of $900^{\circ} \mathrm{C}$-calcined YAG:Eu ${ }^{3+}$ phosphors exhibited a broad band on the long-wavelength side,

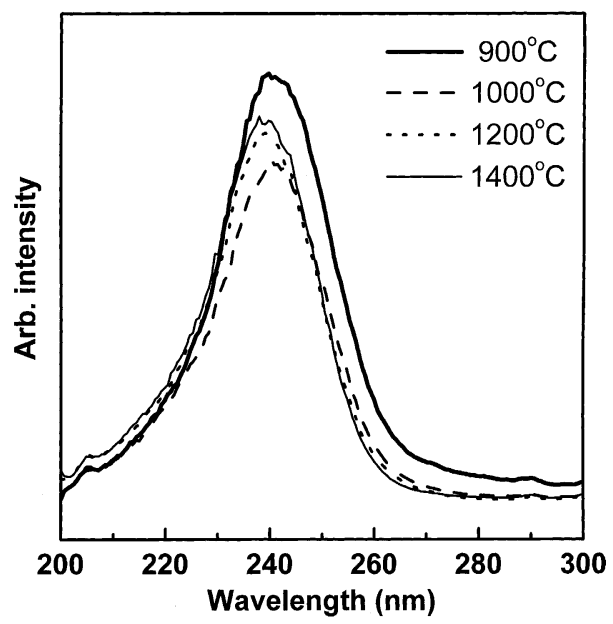

Fig. 5. Excitation spectrum of $\mathrm{Y}_{2.85} \mathrm{Eu}_{0.15} \mathrm{Al}_{5} \mathrm{O}_{12}$ phosphors monitored the emission at $608 \mathrm{~nm}$. These phosphors were prepared via the sol-gel process and calcined at various temperatures. which is possibly related to the charge transfer process in the phosphors. Since the $900^{\circ} \mathrm{C}$-calcined sample had a low crystallinity, its crystal periodicity tended to be disorderly. This led to the production of more possible energy states for the $\mathrm{Eu}^{3+}-\mathrm{O}^{2-}$ pairs, thereby resulting in the broadening of the excitation band. The above results indicate that the precise control of the morphology, particle size, and crystallinity of $\mathrm{YAG}: \mathrm{Eu}^{3+}$ is required for improving their photoluminescence properties.

\section{Conclusions}

Nano-sized YAG:Eu ${ }^{3+}$ phosphors were successfully obtained via a sol-gel process at a temperature as low as $900^{\circ} \mathrm{C}$. The synthesis temperature was much lower than that in the conventional solid-state reaction process. During the gelation process, citric acid and ethylene glycol formed numerous tiny enclosures that trapped the constituent cations, leading to a shortening of the interdiffusion length and an increase in the reactivity of the precursors. The particle size of the sol-gel-derived YAG: $\mathrm{Eu}^{3+}$ phosphors was $40 \mathrm{~nm}$ $\left(900^{\circ} \mathrm{C}\right)$, which was greatly smaller than that of the powders prepared via the solid-state reaction process. The photoluminescence intensity of the sol-gel-derived phosphors was markedly stronger than that of the powders prepared via the solid-state reaction process. This is considered to be attributed to the increased crystallinity and improved distribution of activators in the sol-gel-derived powders. The photoluminescence properties of YAG:Eu ${ }^{3+}$ phosphors were found to be significantly dependent on their morphology and particle size.

\section{References}

[1] L.E. Shea, J. McKittrick, O.A. Lopez, J. Am. Ceram. Soc. 79 (1996) 3257.

[2] J. McKittrick, L.E. Shea, C.F. Bacalski, E.J. Bosze, Displays 19 (1999) 169.

[3] Y.C. Kang, I.W. Lenggoro, S.B. Park, K. Okuyama, J. Phys. Chem. Solids 60 (1999) 1855.

[4] I. Matsubara, M. Parathaman, S.W. Allison, M.R. Cates, D.L. Beshears, D.E. Holcomb, Mater. Res. Bull. 35 (2000) 217.

[5] J.G. Li, T. Ikegami, J.H. Lee, T. Mori, Y. Yajima, J. Mater. Res. 15 (2000) 1864.

[6] N. Matsushita, N. Tsuchiya, K. Nakatsuka, J. Am. Ceram. Soc. 82 (1999) 1977.

[7] Y.C. Kang, Y.S. Chung, S.B. Park, J. Am. Ceram. Soc. 82 (1999) 2056.

[8] Y.C. Kang, I.W. Lenggoro, S.B. Park, K. Okuyama, Mater. Res. Bull. 35 (2000) 789.

[9] J.Y. Choe, D. Ravichandran, S.M. Blomquist, K.W. Kirchner, E.W. Forsythe, D.C. Morton, J. Lumin. 93 (2001) 119.

[10] J.Y. Choe, D. Ravichandran, S.M. Blomquist, D.C. Morton, K.W. Kirchner, M.H. Ervin, U. Lee, Appl. Phys. Lett. 78 (2001) 3800.

[11] C.H. Lu, S.K. Saha, Mater. Res. Bull. 35 (2000) 2135.

[12] A. Kahoul, P. Nkeng, A. Hammouche, F. Naamoune, G. Poillerat, J. Solid State Chem. 161 (2001) 379. 
[13] A. Campero, J. Cardoso, S. Pacheco, J. Sol-Gel Sci. Tech. 8 (1997) 535.

[14] M. Yabuki, R. Takahashi, S. Sato, T. Sodesawa, K. Ogura, Phys. Chem. Chem. Phys. 4 (2002) 4830.

[15] X-ray Powder Data File, Card No. 33-0040, International Centre of Diffraction Data, 1997.
[16] S.K. Ruan, J.G. Zhou, A.M. Zhong, J.F. Duan, X.B. Yang, M.Z. Su, J. Alloys Compd. 275-277 (1998) 72.

[17] S. Shikao, W. Jiye, J. Alloys Compd. 327 (2001) 82.

[18] D. Ravichandran, R. Roy, A.G. Chakhovskoi, C.E. Hunt, W.B. White, S. Erdei, J. Lumin. 71 (1997) 291. 